\title{
Cognitive behavioural therapy (CBT) for carers of patients with Parkinson's disease: a preliminary randomised controlled trial
}

\author{
D L Secker, R G Brown
}

J Neurol Neurosurg Psychiatry 2005;76:491-497. doi: 10.1136/jnnp.2004.042291

See end of article for authors' affiliations ....................

Correspondence to: R G Brown, Department of Psychology PO77, Institute of Psychiatry, De Crespigny Park, Camberwell, London SE5 8AF, UK; r.brown@iop.kcl. ac.uk

Received 29 March 2004 In revised form 25 June 2004 Accepted 15 July 2004

\begin{abstract}
Objective: Most individuals with Parkinson's disease live in their own homes cared for by a family member. Providing such long term care can be a source of significant stress, with many carers experiencing sleep difficulty, depression, anxiety, loneliness, and other symptoms of psychological strain. Cognitive behavioural therapy (CBT) is one of the most widely used psychological treatments in clinical use today, with applications across the full range of clinical conditions. It has been previously used in the management of other carer groups. The present study sought to evaluate the efficacy of CBT in treating psychological distress in a group of Parkinson's disease carers.

Method: A total of 30 carers scoring at caseness level on the 28 item General Health Questionnaire (GHQ-28) were randomised to receive either a course of 12-14 sessions of CBT or to a no-treatment control group.

Results: Although some change was observed in both groups, significantly greater improvement on the GHQ-28 was observed after three months in the CBT treated group. Similar findings were observed in measures of caregiver strain and subjective burden, with the benefits being maintained over a subsequent three month follow up period.

Conclusions: These results offer preliminary support to the value of a CBT approach in the management of psychological morbidity in Parkinson's disease carers. Further larger scale research is needed in the future to examine the generalisability of the findings to a broader range of carers, assess the longer term impact on outcome in carers and those with Parkinson's disease, and explore how CBT can be best delivered in the most cost effective manner.
\end{abstract}

$P$ arkinson's disease is a chronic progressive and currently incurable neurological illness. It affects approximately 120000 individuals in the UK alone with over 10000 new cases per year. ${ }^{12}$ The prevalence increases with age, from one per 100 below the age of 60 years to 20 per 1000 over the age of 85 years. ${ }^{3}$ In the early stages of Parkinson's disease medication enables patients to remain functionally independent. With progression, however, drug treatment becomes less effective, motor symptoms worsen, and dependency increases. As with most chronic diseases, the major burden of informal care falls on the spouse and other family members. Care responsibilities can include providing assistance with mobility and transport, managing medical regimens, coordinating and communicating with various health professionals, and managing financial resources. Carers often also find themselves taking responsibility for duties once performed by the individual with Parkinson's disease.

Assistance with physical care such as feeding, washing, and grooming become necessary as the disease progresses, and in the complex stage of Parkinson's disease, toileting and lifting is required. One study indicated that the mean number of care-related activities performed ranged from 11 per day in early Parkinson's up to 30 per day in late stage disease. ${ }^{4}$ In addition to the physical and time demands of caring, carers also have to cope with a range of non-motor symptoms associated with Parkinson's disease such as cognitive impairment, depression, anxiety, hallucinations, sleep disturbance, and behavioural change. ${ }^{5}$ These can require emotional as well as practical support and supervision from the carer. Finally, the demands of caring can lead to restriction of other areas of the carer's life including work, social, and recreational function, ${ }^{6}$ reducing their quality of life.
Caregiving can adversely affect the physical and psychological health of the carer. Tension and worry increase as the individual with Parkinson's disease progresses through the phases of the disease, ${ }^{4}$ while the overall level of psychiatric morbidity in those providing the highest level of care increases almost fivefold compared to non-carer spouses. ${ }^{7}$ Psychiatric and behavioural symptoms in the patient are a major source of carer distress and can outweigh that caused by the physical symptoms of Parkinson's disease. ${ }^{8}$ Patient depression is an important predictor of caregiver mood. ${ }^{9}$ Other effects on Parkinson's disease caregivers include worsened family functioning, ${ }^{10}$ self-reported decline in physical health, ${ }^{4}$ and decreased marital satisfaction. ${ }^{11}$ Many carers are unprepared for these dramatic changes and those who fail to adjust initially often remain unable to cope in the later stages. ${ }^{12}$

Carer stress can also have consequences for the wellbeing of the individual with Parkinson's disease. Caregiver fatigue and ill health can impact on the quality of care offered, and continual stress in the carer can lead to anger and resentment directed towards the individual with Parkinson's disease. ${ }^{13}$ If carer stress is not adequately addressed with appropriate support, premature residential placement of the patient may occur as is observed in other chronic disorders. ${ }^{14}$

All of these issues are contained within stress-process models of family caregiving such as that of Pearlin and colleagues. $^{15}$ These models describe how primary and secondary stressors arising from the patient's symptoms,

Abbreviations: $\mathrm{CBI}$, Caregiver Burden Inventory; $\mathrm{CBT}$, cognitive behavioural therapy; CDR, Clinical Dementia Rating (scale); CSI, Caregiver Strain Index; GHQ, General Health Questionnaire 
the carer's appraisal of these, and their combined impact on the carer's life (caregiver burden) can lead to a variety of adverse caregiver outcomes including physical and psychiatric ill health. This relationship can be mediated both by situational factors, such as the quality and quantity of additional support and financial resources, and by individual factors such as the caregiver's coping style. Depending on the interplay between these factors over time, two main patterns can be observed: stress containment or stress proliferation. Interventions aimed at caregivers have been implicitly or explicitly based within such a framework. Their goal is typically to reduce the sources of stress proliferation and enhance the resources that lead to containment. Although they do not aim to alter the patient's underlying condition they may seek to modify either the carer's appraisal of the problems or the broader impact of stressors on the carer's life.

Most interventions have combined educational components to enhance understanding and practical coping strategies with broader cognitive behavioural approaches both to reduce the sources of secondary stress and to encourage stress containment. Such interventions have been applied to a range of carer groups including families of individuals with schizophrenia, ${ }^{16}{ }^{17}$ and more recently to carers of individuals with Alzheimer's disease and other chronic conditions. These latter studies have employed both group $^{18-20}$ and individual ${ }^{21} 22$ therapy. A small study of group treatment for Parkinson's disease carers ${ }^{23}(n=17)$ compared the impact of eight psychologically focused sessions with eight sessions focused on aspects of practical management. Allocation was based on where the carer lived and not individually randomised. The results were suggestive of improvement in the psychological group, although only a third of participants reported clinically significant distress on entry. The authors of the study acknowledged the limitations of the study and the need for formal trials.

The current study describes the evaluation of individual psychological treatment for Parkinson's disease carers suffering from significant psychological morbidity. Cognitive behavioural therapy (CBT) was chosen as being the most widely used and best evaluated psychological intervention currently available. CBT seeks to develop both cognitive and behavioural skills to cope with current stressors, making it particularly suitable to the complex demands and stresses of the caregiving role. The study design was modelled on that of Marriott and colleagues ${ }^{22}$ with Alzheimer's disease carers, although the content of the therapy itself was adapted to meet the anticipated needs of the Parkinson's disease carers. The present study applied an individualised approach to the delivery of therapy rather than following a prescribed treatment protocol making it more typical of standard clinical practice. Outcome was measured in terms of both general psychological distress and clinical caseness, and more specific aspects of carer burden and strain.

\section{METHOD}

\section{Recruitment and randomisation}

Carers were either referred by a clinician (neurologist or nurse specialist) following routine clinical contact, or selfreferred after seeing advertisements in the newsletters of local branches of the Parkinson's Disease Society (UK). The advertisement identified "emotional strain and stress" associated with caring, and the treatment's aims of "improving emotional well-being and coping". The primary inclusion criterion was a score of 5 or more ("case" level problems) on the 28 item General Health Questionnaire (GHQ-28) ${ }^{24}$ using the binary GHQ "0011" scoring method. In addition, participants had to be $(a)$ the primary carer to the individual with Parkinson's disease and living with them and $(b)$ willing to actively engage in at least 12 weekly therapy sessions over a three month period. Carers were not considered for the study if the referrer or investigator judged that they lacked sufficient fluency in spoken English to engage in therapy.

In order to ensure an equal number in each group and to manage the clinical resources available to the trial, participants were randomised in blocks of two using sealed envelopes, with one member of each consecutive pair receiving $\mathrm{CBT}$ and the other allocated to the no-treatment control group. Because of the nature of the study, neither the therapist nor the carer was blind to allocation.

\section{Assessment measures}

Prior to randomisation at baseline (T0) all caregivers were assessed on a series of standard measures. Because of the non-blinded nature of the study, and to avoid possible investigator bias, only self-report measures were used to measure outcome. The principal outcome measure used for the carer was the GHQ- $28,{ }^{24}$ a widely used screening tool designed to measure clinical caseness and psychological distress in the general population. Two scores were calculated, the binary scored total used to identify caseness, and a total score based on the full Likert $0-3$ scoring range. In addition, subscale scores were derived for somatic symptoms, anxiety and insomnia, social dysfunction, and severe depression. These subscores were included as secondary outcomes, in addition to the 15 item Geriatric Depression Scale (GDS15), ${ }^{25}$ Caregiver Strain Index $(\mathrm{CSI})^{26}$ and the Caregiver Burden Inventory (CBI). ${ }^{27}$ All assessments were repeated by postal questionnaires at end of treatment in the CBT group or after three months in the controls $(\mathrm{T}+3)$ and again in all participants six months $(\mathrm{T}+6)$ after baseline assessment. Additional demographic and health related information was collected on all caregivers at T0: age, sex, years of education, whether they were a sole carer, and their own health status. This latter measure was derived from the Global Physical Health Rating Scale from the Older Americans Resources and Services (OARS) Multidimensional Functional Assessment Questionnaire. ${ }^{28}$ This provides a checklist of 11 common health complaints in older adults. The number of complaints was taken as an index of the total burden of physical ill health.

The individuals with Parkinson's disease were also assessed at baseline to provide descriptive details. Demographic and health information was collected as for the carers. In addition, the stage of parkinsonian progression (stages I-V) was assessed using the Hoehn and Yahr scale. ${ }^{29}$ Dependency was assessed by the investigator with the 100 point Schwab and England scale. ${ }^{30}$ Cognitive function was assessed using the Standardized Mini Mental State Examination (SMMSE), ${ }^{31}$ and depression using the GDS-15. The presence and severity of dementia was rated by the investigator using the Clinical Dementia Rating Scale (CDR). ${ }^{32}$

\section{Therapy}

Therapy commenced within two weeks of randomisation. Where the care receiver required supervision, sitters or additional care was arranged through local services. The mean number of therapy sessions was 14.7 (SD 2.5), range 11-19, typically given at one week intervals. The treatment package consisted of eight modules, each of which could be delivered in one session, spread over several or even omitted, depending on the nature and severity of the problems and the individual progress of the carer. Each module targeted a specific stressor and/or trained a new adaptive coping method, and was supported by targeted homework assignments for the carer to practise between sessions. The choice and order of modules was based on a collaborative prioritisation of needs conducted early in treatment. A brief 
Table 1 Modules used in the trial of CBT for Parkinson's carers

\begin{tabular}{|c|c|}
\hline Module & Content \\
\hline $\begin{array}{l}\text { Education and introduction to } \\
\text { cognitive behavioural therapy }\end{array}$ & $\begin{array}{l}\text { Factual misperceptions are a common source of carer stress and should be dealt with outright. In the first session questions } \\
\text { about Parkinson's disease were discussed fully and relevant information was given to take home. The module progressed to a } \\
\text { discussion about the therapy itself, and a review of the carer's goals and expectations. This provides a non-threatening forum } \\
\text { for the initial development of rapport and set a constructive collaborative precedent for the coming sessions }\end{array}$ \\
\hline $\begin{array}{l}\text { Accessing community resources } \\
\text { and supports }\end{array}$ & $\begin{array}{l}\text { A central characteristic of Parkinson's disease carers who cope well is a full understanding of the multidisciplinary network and } \\
\text { other support systems. In this module, the carer's support network was reviewed and information provided where necessary. } \\
\text { The carer worked on how to access and communicate effectively with available services }\end{array}$ \\
\hline Pleasant activity scheduling & $\begin{array}{l}\text { This module consisted primarily of }(a) \text { encouraging the carer to make designated times for recreation without the person they } \\
\text { care for, doing things they themselves enjoy and }(b) \text { designating times to engage in enjoyable things with the person they care } \\
\text { for that do not involve normal care duties }\end{array}$ \\
\hline Relaxation training & This module focused on practical strategies for the relief of anxiety and tension \\
\hline & $\begin{array}{l}\text { A common problem for caregivers of chronically ill patients is the lack of restorative unbroken sleep. This module covered } \\
\text { several basic skills to help the carer to improve their own sleep-preparation behaviour and also ways to manage the sleep } \\
\text { problems of the individual with Parkinson's disease }\end{array}$ \\
\hline $\begin{array}{l}\text { Identifying and challenging } \\
\text { negative thoughts and feelings }\end{array}$ & $\begin{array}{l}\text { This module was targeted at those carers with recurrent negative thinking patterns contributing to stress. This was most suitable } \\
\text { for carers presenting with depression, anxiety, and persistent worry. Skills taught included identifying and rating negative } \\
\text { feelings, automatic thought recording, and rationalising guilt }\end{array}$ \\
\hline $\begin{array}{l}\text { Challenging maladaptive rules } \\
\text { and core beliefs }\end{array}$ & $\begin{array}{l}\text { Carers who benefited from module } 6 \text { were encouraged to progress to a more complex level of cognitive therapy, including } \\
\text { awareness of intermediate beliefs such as rules and conditional assumptions around caring, and to the restructuring of core } \\
\text { schematic beliefs (for example, "I am a bad carer", and "There is no future") }\end{array}$ \\
\hline $\begin{array}{l}\text { Review, planning for the future, } \\
\text { and ending of treatment }\end{array}$ & $\begin{array}{l}\text { This final module reviewed all of the previous modules, and created a therapeutically appropriate termination of therapy for the } \\
\text { carer. The need for supplementary sessions was addressed at this stage. Long term goal planning was addressed. Extra } \\
\text { assistance was provided to those carers supporting someone in the near-palliative or very advanced stages of Parkinson's } \\
\text { disease, such as approaching the issues of nursing home placement, legal issues such as will making, and structured planning } \\
\text { for the future }\end{array}$ \\
\hline
\end{tabular}

summary of the modules and their content is presented in table 1. These drew upon standard CBT practice and on a number of additional sources including published trials, empirical studies, and treatment guides. ${ }^{17}{ }^{22}{ }^{33-38}$ The therapist (DS) was a clinical psychologist with approximately three years' experience working with older adults. Further details of the therapy modules are available from the corresponding author.

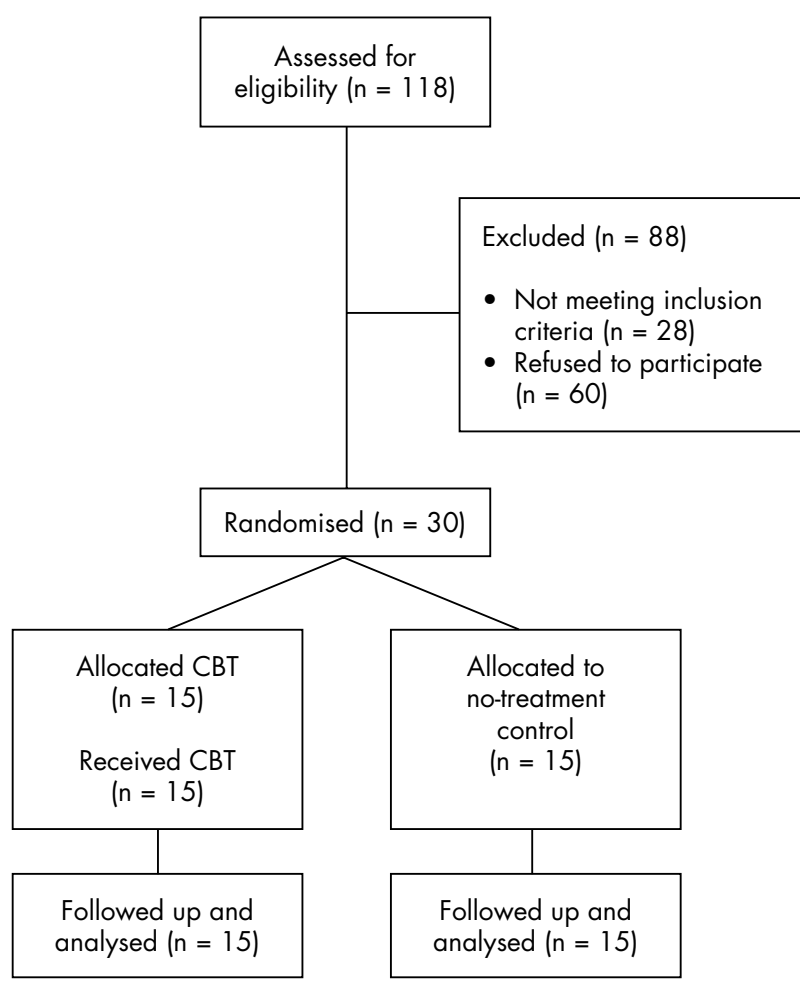

Figure 1 CONSORT diagram showing the flow of participants through the trial.
All control participants were offered the opportunity to attend a series of group sessions at the end of the study (that is, 6-18 months after inclusion). Approximately half took up this opportunity. The availability of the alternative treatment may make it more appropriate to consider the no-treatment control as a partial waiting list control.

\section{RESULTS}

\section{Sample size and randomisation}

On the basis of Marriott et al' $\mathrm{s}^{22}$ findings it was estimated that 15 participants per group would be adequate to detect a difference between CBT and control at treatment endpoint with $90 \%$ power and $\alpha=0.05$ (two tailed). A total of 118 carers were referred or self-referred over a period of 12 months with 30 entering the study and remaining through to follow up (see fig 1). Reasons for exclusion were a GHQ-28 score of less than $5(\mathrm{n}=9)$ and the carer not living with the individual with Parkinson's disease $(\mathrm{n}=19)$.

\section{Sample characteristics}

The characteristics of the participating carers are shown in table 2 . All but three of the carers were women, the majority being the spouse or partner of the care receiver with about half being the sole carer. Approximately half of the carers remained in full or part-time work. The two carer groups did not differ significantly $\left(t_{28}<1.3, \mathrm{p}>0.10\right)$ in age or years of education or number of health problems $(U=64.5, z=-1.0$, $\mathrm{p}>0.10)$. The majority of care receivers were men and all but two in each group were unemployed or retired. The care recipients of the carers randomised to CBT treatment tended to have a slightly longer duration of Parkinson's disease with a correspondingly increased level of disablement and cognitive impairment. However, none of the differences between the groups was significant (in all comparisons $\mathrm{p}>0.10)$.

\section{Caregiver outcome measures at T0}

The scores of the caregivers at T0 and subsequent assessments are shown in table 3. Mean scores of the CBT and control groups were compared using independent $t$ tests. None of the measures differed significantly (in all instances $\left.t_{28}<1.3, \mathrm{p}>0.10\right)$. However, there was a trend across many 
Table 2 Caregiver and care receiver characteristics in the treatment and control groups (frequencies/mean (SD))

\begin{tabular}{|c|c|c|}
\hline & $\begin{array}{l}\text { Treatment group } \\
(\mathrm{n}=15)\end{array}$ & $\begin{array}{l}\text { Control group } \\
(\mathrm{n}=15)\end{array}$ \\
\hline \multicolumn{3}{|l|}{ Caregivers } \\
\hline Age (years) & $59.1(12.2)$ & $58.9(11.4)$ \\
\hline Education (years) & $12.6(3.3)$ & $12.9(2.4)$ \\
\hline OARS (number of health conditions) & $4.5(3.1)$ & $6.4(4.8)$ \\
\hline Sex (number of women) & $13 / 15$ & $14 / 15$ \\
\hline Employment (number in work) & $7 / 15$ & $6 / 15$ \\
\hline Sole carer (number) & $9 / 15$ & $7 / 15$ \\
\hline Relationship to patient (number spouse/partner) & $13 / 15$ & $13 / 15$ \\
\hline \multicolumn{3}{|l|}{ Care receivers (at TO) } \\
\hline Age (years) & $69.7(8.2)$ & $67.0(6.9)$ \\
\hline Education (years) & $12.3(2.7)$ & $12.1(2.1)$ \\
\hline Years since diagnosis & $10.0(7.5)$ & $8.5(4.0)$ \\
\hline Hoehn and Yahr Stage & $3.0(1.2)$ & $2.5(0.9)$ \\
\hline Schwab and England ADL & $47.3(24.9)$ & $59.3(21.3)$ \\
\hline SMMSE (total) & $22.8(7.0)$ & $25.9(3.6)$ \\
\hline \multicolumn{3}{|l|}{ CDR (number) } \\
\hline No/questionable dementia & $10 / 15$ & $9 / 15$ \\
\hline Mild dementia & $3 / 15$ & $5 / 15$ \\
\hline Moderate dementia & $2 / 15$ & $1 / 15$ \\
\hline Severe dementia & $0 / 15$ & $0 / 15$ \\
\hline GDS-15 (total) & $7.0(3.4)$ & $5.4(2.7)$ \\
\hline OARS (number of health conditions) & $7.1(3.6)$ & $8.3(3.1)$ \\
\hline Sex (number women) & $1 / 15$ & $2 / 15$ \\
\hline Employment (number in work) & $2 / 15$ & $2 / 15$ \\
\hline
\end{tabular}

measures for the treatment group to show worse psychological function than the control group at T0.

\section{Statistics}

In order to derive a simple summary measure for evaluating the impact of treatment, ${ }^{39}$ difference scores were calculated between T0 and T3 for the primary and secondary outcome measures. The distributions of these differences were examined for normality and for the presence of outliers. For all measures, the data were judged suitable for parametric analysis. However, because of the trend towards baseline differences in the two groups, change scores were compared using univariate analysis of variance with T0 scores as a covariate. A similar analysis was conducted to assess any change between $\mathrm{T}+3$ and $\mathrm{T}+6$ months although without a covariate. Given the preliminary nature of the study no adjustments for multiple comparisons were made to the critical $\mathrm{p}$ value $(\mathrm{p}<0.05)$ for evaluating the various secondary outcome measures.

\section{Impact of treatment}

Carers in the treatment group showed a large mean reduction in their total GHQ-28 score of 20.7 (SD 14.5) points (95\% confidence interval (CI) 12.9 to 28.8) compared with a decrease of only 6.8 (13.9) points ( $95 \%$ CI -0.9 to 14.5 ) in the control group $\left(F_{1,29}=9.1, \mathrm{p}<0.01\right)$. Secondary analyses of the GHQ-28 subscale scores revealed greater mean change in the treatment group for somatic symptoms $\left(F_{1,29}=10.8\right.$, $\mathrm{p}<0.01)$, anxiety and insomnia $\left(F_{1,29}=5.8, \mathrm{p}<0.05\right)$, and social dysfunction $\left(\mathrm{F}_{1,29}=6.3, \mathrm{p}<0.05\right)$ but not for symptoms of severe depression $\left(F_{1,29}<1, \mathrm{p}>0.10\right)$.

Broadly comparable results were obtained with the other secondary outcome measures. The treatment group showed a significantly greater decrease in both caregiver burden (mean decrease: treatment group 29.8 (20.1), 95\% CI 16.9 to 42.5; control group -1.9 (14.6), 95\% CI -10.3 to 6.6$)\left(F_{1,25}=23.1\right.$, $\mathrm{p}<0.001$ ) and caregiver strain (treatment group 4.1 (4.2), $95 \%$ CI 1.7 to 6.4 ; control group -0.3 (1.3), $95 \%$ CI -1.1 to $0.4)\left(F_{1,29}=12.4, \mathrm{p}<0.01\right)$. In contrast changes in depression measured by the GDS-15 were small and did not differ between the two groups (treatment group $2.2(4.3), 95 \%$ CI -0.2 to 4.8 ; control group $0.7(2.4)$, $95 \% \mathrm{CI}-0.7$ to 2.1$)$ $\left(F_{1,27}<1, \mathrm{p}>0.10\right)$.

Analysis of differences between $\mathrm{T}+3$ and $\mathrm{T}+6$ failed to reveal any further significant change in mean scores for the GHQ or any of the secondary outcome measures (in all cases $\mathrm{p}>0.10$ ). Both groups remained stable with mean group differences evident at $\mathrm{T}+3$ remaining at $\mathrm{T}+6$.

Table 3 Primary and secondary outcome measures for the treatment $(n=15)$ and control $(n=15)$ groups

\begin{tabular}{|c|c|c|c|c|c|c|}
\hline & \multicolumn{2}{|l|}{ TO } & \multicolumn{2}{|l|}{$T+3$ months } & \multicolumn{2}{|l|}{$T+6$ months } \\
\hline & $\begin{array}{l}\text { Treatment } \\
\text { Mean (SD) }\end{array}$ & $\begin{array}{l}\text { Control } \\
\text { Mean (SD) }\end{array}$ & $\begin{array}{l}\text { Treatment } \\
\text { Mean (SD) }\end{array}$ & $\begin{array}{l}\text { Control } \\
\text { Mean (SD) }\end{array}$ & $\begin{array}{l}\text { Treatment } \\
\text { Mean (SD) }\end{array}$ & $\begin{array}{l}\text { Control } \\
\text { Mean (SD) }\end{array}$ \\
\hline GHQ-28 (Likert scored) (Total) & $36.9(11.5)$ & 33.7 (13.8) & $16.2(10.4)$ & $26.6(9.6)$ & $15.8(9.9)$ & $26.2(13.4)$ \\
\hline GHQ Somatic symptoms & $7.1(4.5)$ & $7.2(5.4)$ & $2.8(2.9)$ & $7.5(3.8)$ & $3.6(3.9)$ & $7.2(4.1)$ \\
\hline GHQ Anxiety and insomnia & $12.7(2.9)$ & $11.1(4.9)$ & $5.8(3.9)$ & $8.5(4.3)$ & $5.2(3.3)$ & $8.6(4.6)$ \\
\hline GHQ Social dysfunction & $11.6(3.1)$ & $10.1(3.3)$ & $5.5(3.8)$ & $8.5(2.4)$ & $5.2(3.5)$ & $8.5(3.2)$ \\
\hline GHQ Severe depression & $5.3(5.6)$ & $2.9(3.9)$ & $2.1(3.1)$ & $2.1(2.2)$ & $1.8(2.3)$ & $1.9(3.3)$ \\
\hline GDS-15 & $7.0(3.7)$ & $5.8(3.5)$ & $4.4(3.7)$ & $4.7(2.9)$ & $3.5(3.1)$ & $4.7(3.3)$ \\
\hline CSI & $8.7(2.7)$ & $7.2(3.4)$ & $4.6(2.8)$ & $7.5(3.4)$ & $5.5(2.0)$ & $7.9(3.1)$ \\
\hline $\mathrm{CBI}$ & $54.5(15.2)$ & $48.0(17.9)$ & $24.8(10.2)$ & $48.9(18.5)$ & $25.5(12.5)$ & $51.1(19.7)$ \\
\hline
\end{tabular}

CBI, Caregiver Burden Inventory; CSI, Caregiver Strain Index; GDS, Geriatric Depression Scale; GHQ, General Health Questionnaire. 
Although mean levels and change scores can indicate overall morbidity and response to treatment, they do not provide information relating to clinical significance and individual responses. Case level morbidity on the GHQ-28 was the primary inclusion criterion for the study, with all participants showing a binary coded score of greater than 4 at entry. At $\mathrm{T}+3$ only $3 / 15(20 \%)$ of the treatment group remained "cases" compared with 10/15 (67\%) of the controls $\left(\chi(1)^{2}=6.7, \mathrm{p}<0.05\right)$. At $\mathrm{T}+6$ the figures were $3 / 15(20 \%)$ and $7 / 15(47 \%)$, respectively, a difference that was no longer significant $\left(\chi(1)^{2}=2.4, \mathrm{p}>0.10\right)$. Figure 2 illustrates the patterns of individual change in GHQ-28 score across the three assessments. In the treatment group, 14/15 carers showed a decrease in GHQ-28 score over the course of therapy, with 11 recording a score of less than 2 at the end of treatment. Only one carer failed to show any overall improvement with treatment at $\mathrm{T}+3$. In the control group 9/15 carers showed some degree of improvement, one showed no change, and four deteriorated. In keeping with the group mean data, the status of most carers in both groups remained relatively stable between $\mathrm{T}+3$ and $\mathrm{T}+6$, although some marked fluctuations were observable in both groups.

\section{DISCUSSION}

Existing research has reliably demonstrated increased levels of subjective burden, caregiver strain, and distress in Parkinson's disease carers. ${ }^{49-11} 13^{40-46}$ The present study is the first randomised controlled trial of a psychological intervention for such problems. Compared with no-treatment, the intervention led to both statistically and clinically significant reductions on a range of outcomes with improvement being maintained for a period of three months after the end of therapy. This discussion will focus on a number of issues relating to the study, its context, and implications for future research.

First to consider are the nature and severity of the problems the carers presented. All scored above the cut-off of 4 recommended for the GHQ-28, although it is clear from fig 2 that the majority exceeded this threshold by a substantial amount. In agreement with this, the level of caregiver stress was also high, with $90 \%$ scoring above 4 on the CSI. Depression, in contrast, was a less consistent feature, with only $50 \%$ scoring above 6 , a cut-off with good specificity

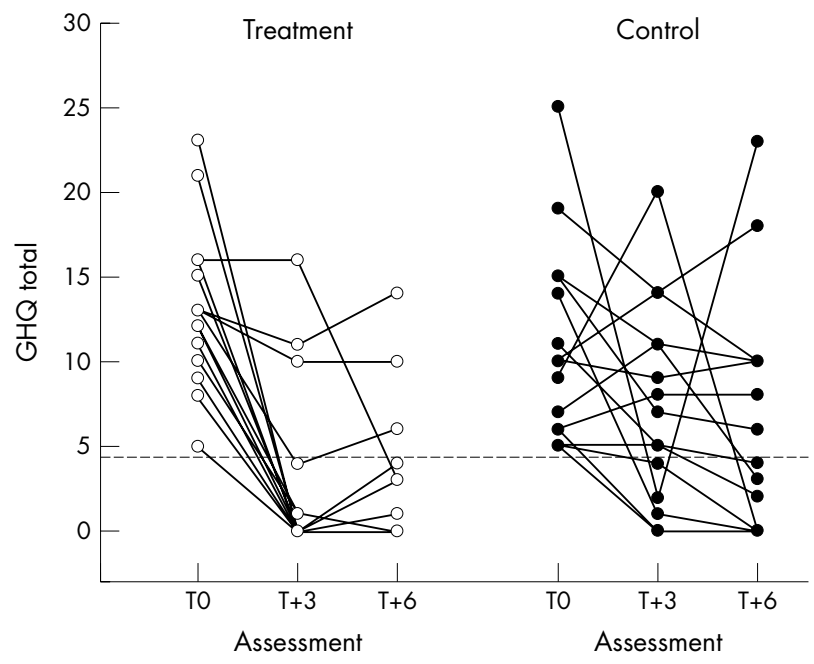

Figure 2 Individual GHQ-28 (binary coded) scores of carers in the treatment and control groups over the trial period. The dashed line indicates the level of clinical "caseness". for identifying clinically significant depression. ${ }^{47}$ Thus, while depression was an important part of the profile of some carers it was not a key feature of the sample as a whole. Thus, although depression can be a significant problem, it would not have been appropriate to choose it as the primary target for therapy (or criterion for inclusion) in the present sample. The symptom profile of the carers suggests that treatment should target broader aspects of carer stress with outcome measures chosen accordingly.

From the outset, the treatment approach was designed to be flexible and sensitive to the needs of individual carers. Treatment centred on a set of modules that could be delivered in a way that suited the particular problems of the carer and their individual rate of progress. No attempt was made to standardise the content, order, or duration of the modules. Rather, the trial attempted to use standard best clinical practice by a trained clinical psychologist within the framework offered by CBT. A disadvantage of such an approach is that it was not possible to evaluate the contribution of any single component of the treatment or other aspect of its delivery. Such matters would need to be considered in future studies. Nevertheless, as a pragmatic trial reflecting standard CBT practice, the results should be representative of what might be found in routine management of carers if psychological support was available. The results indicate that a practically realistic course of $\mathrm{CBT}$ can be effective in dramatically reducing the level of psychological morbidity and stress in Parkinson's disease carers. The high levels of problems reported on entry to the study were markedly reduced or even eliminated in most carers with all but three falling below the level of clinical caseness at the end of treatment. The change was manifest in overall GHQ-28 scores and in the three subscales that were elevated at entry. Similar changes were observed for the CSI and CBI measures giving a picture of wide ranging and clinically significant improvement in the group randomised to treatment.

In a clinical trial, any such gains need to be compared with changes observed in the control group. While all of the treatment effects were significant relative to the control group, those not receiving treatment still showed some improvement over the first three months of the study, with approximately a third no longer meeting GHQ caseness criteria at $\mathrm{T}+3$, with further improvement during follow up. It is possible only to speculate on the reasons for this improvement. The positive impact of being in a trial on reported symptoms is well known, even when, as in this case, there is no placebo treatment (see below). Another possibility is that carers originally sought help at a time of acute stress, for example with a specific care related or secondary problem causing the carer to feel overwhelmed. Over time such stress may lessen with resolution or improvement of the problem. The work of Aneshensel and colleagues ${ }^{48}$ illustrated such longitudinal changes in caregiving response, although there is some evidence that general coping style and level of depression remain fairly constant in carers over time. ${ }^{49}$ The current study also suggests that there are limits to spontaneous change as no decreases were observed in the mean levels of either carer burden or strain in the control group, and only a slight reduction in depression.

CBT aims to help the client to develop skills that they can use outside of the therapy session and continue using when therapy ends. An important aspect of evaluation therefore, is whether any treatment gains were maintained. In practice, the group mean scores (table 3 ) and the individual data (fig 2) suggest that most carers remained relatively stable between $\mathrm{T}+3$ and $\mathrm{T}+6$, although there was more marked variability in the control group. Importantly, however, the treatment group continued to show improved function compared with the control group at $\mathrm{T}+6$ on the majority of 
indices, with no evidence of a return to baseline levels of morbidity.

Although the results were encouraging and consistent with trials of CBT in other carer groups, ${ }^{22}{ }^{50}$ the study is ultimately limited by aspects of sample size, duration of follow up, and sampling. The small sample size increases the chance of type I error. However, the effect sizes of treatment for the primary and secondary outcome measures were consistent with previous research and were all large $(>1.0)$ with the exception of the depression measures. The breadth of impact on a range of indices tapping different facets of caregiver outcome also suggests that the finding were reliable. One other limitation of the sample size was that it precluded the examination of factors that might predict individual response to treatment. For example, a previous study evaluating treatment of caregiver depression found that CBT produced significantly superior results in carers who had been performing the role for more than 44 months. ${ }^{50}$ Future research in large groups of patients would need to examine such factors to help decide how best to target therapy in clinical practice.

The follow up duration of three months after the end of treatment was less than desirable in a clinical context. Future studies should seek to follow up participants for at least 12 months to provide a more clinically useful picture of treatment efficacy. Finally it is acknowledged that no attempt was made to ensure that the participants were representative of the wider population of Parkinson carers. They tended to be relatively young and well educated and were predominantly women. It is uncertain whether the latter fact reflects a real gender difference in the severity of morbidity, burden, and strain as suggested by previous research ${ }^{51}{ }^{52}$ or a sex difference in coping and help seeking behaviour between male and female carers. ${ }^{53}$ Future studies will need to ensure inclusion of a more representative sample of caregivers to fully test the generalisability of the treatment.

In relation to trial design, the present study did not include an attention control condition, relying instead on a comparison between CBT and no-treatment (or partial waiting list). However, the control condition reflects the reality of therapy provision for the vast majority of caregivers. The issue of control group was addressed more fully in the trial of Marriott and colleagues ${ }^{22}$ which included both an attention control group and a non-treatment group but found no difference between the two. This suggests that attention placebo, or simple weekly respite, is unlikely to be a major factor in these studies. It remains for future research to determine what proportion of the clinical gain is specific to the CBT component and how much is due to non-specific aspects of therapy. Nor did the study allow us to assess the contribution of any of the individual therapy modules. Future research might investigate such issues to help in the planning and delivery of more effective treatment.

Finally, although the present study was able to demonstrate the efficacy of a CBT approach to managing psychological problems in a group of Parkinson's disease caregivers, the evidence will be of little value if it is not translated into clinical practice. Access to clinical psychology services by carers can be difficult with substantial waiting times for treatment. Future research may need to explore alternative methods of delivery to improve access to treatment, such as group treatment employed successfully in other carer populations, ${ }^{18-20}$ or the use of specialist nurses trained in CBT.

\section{ACKNOWLEDGEMENTS}

Our deepest thanks are given to Anna Blockley for nursing support and help with recruitment. We would also like to thank Dr Chris Clough, Dr K Ray Chaudhuri and Dr Robert Howard for their involvement in the planning of this study.

\section{Authors' affiliations}

D L Secker, R G Brown, Department of Psychology, Institute of Psychiatry, King's College London, London, UK

This study was conducted using funds provided by the UK Parkinson's Disease Society (PDS) through a GlaxoSmithKline Research Award.

Competing interests: none declared

\section{REFERENCES}

1 MacDonald BK, Cockerell OC, Sander JW, Shorvon SD. The incidence and lifetime prevalence of neurological disorders in a prospective communitybased study in the UK. Brain 2000;123(Pt 4):665-76.

2 Schrag A, Ben Shlomo Y, Quinn NP. Cross sectional prevalence survey of idiopathic Parkinson's disease and Parkinsonism in London. BM 2000;321:21-2.

3 Mutch WJ, Dingwall-Fordyce I, Downie AW, et al. Parkinson's disease in a Scottish city. Br Med J (Clin Res Ed) 1986;292:534-6.

4 Carter JH, Stewart BJ, Archbold PG, et al. Living with a person who has Parkinson's disease: the spouse's perspective by stage of disease. Mov Disord 1998;13:20-8.

5 Shulman LM, Taback RL, Bean J, et al. Comorbidity of the nonmotor symptoms of Parkinson's disease. Mov Dis 2001;16:507-10.

6 Lawton MP, Moss M, Duhamel LM. The quality of daily life among elderly care receivers. J Appl Gerontol 1995; 14:150-71.

7 O'Reilly F, Finnan F, Allwright S, et al. The effects of caring for a spouse with Parkinson's disease on social, psychological and physical well-being. $\mathrm{Br} J \mathrm{Gen}$ Pract 1996;46:507-12.

8 Aarsland D, Larsen JP, Karlsen K, et al. Mental symptoms in Parkinson's disease are important contributors to caregiver distress. Int J Geriatr Psychiatry 1999; 14:866-74

9 Miller E, Berrios GE, Politynska BE. Caring for someone with Parkinson's disease: factors that contribute to distress. Int J Geriatr Psychiatry 1996;11:263-8.

10 McRae C, Sherry P, Roper K. Stress and family functioning amongst caregivers of persons with Parkinson's disease. Parkinsonism Relat Disord 1999;5:69-75.

11 Hunter J. Parkinson's disease: an investigation of relevant marital and family factors. Diss Abstr Int 1990;51:988.

12 Speer DC. Predicting Parkinson's disease patient and caregiver adjustment: preliminary findings. Behav Health Aging 1993;3:139-46.

13 Davies ADM, Cousins R, Turnbull CJ, et al. The experience of caregiving in Parkinson's disease. In: Purcival R, Hobson P, eds. Parkinson's disease: studies in psychological and social care. Leicester: BPS Books, 1999:154-98.

14 Teri L. Behavior and caregiver burden: Behavioral problems in patients with Alzheimer disease and its association with caregiver distress. Alzheimer Dis Assoc Dis 1997:11:S35-S38.

15 Pearlin LI, Mullan JT, Semple SJ, et al. Caregiving and the stress process: an overview of concepts and their measures. Gerontologist 1990;30:583-94.

16 Barrowclough C, Tarrier N, Lewis S, et al. Randomised controlled effectiveness trial of a needs-based psychosocial intervention service for carers of people with schizophrenia. Br J Psychiatry 1999;174:505-11.

17 Tarrier N, Barrowclough C. Family interventions for schizophrenia. Behav Modif 1990; 14:408-40.

18 Gendron C, Poitras L, Dastoor DP, et al. Cognitive-behavioral group intervention for spousal caregivers: findings and clinical considerations. Clin Gerontologist 1996;17:3-19.

19 Ostwald SK, Hepburn KW, Caron W, et al. Reducing caregiver burden: a randomized psychoeducational intervention for caregivers of persons with dementia. Gerontologist 1999:39:299-309.

20 Hebert R, Levesque L, Vezina J, et al. Efficacy of a psychoeducative group program for caregivers of demented persons living at home: a randomized controlled trial. J Gerontol B Psychol Sci Soc Sci 2003;58:S58-S67.

21 Chang BL. Cognitive-behavioral intervention for homebound caregivers of persons with dementia. Nurs Res 1999;48:173-82.

22 Marriott A, Donaldson C, Tarrier N, et al. Effectiveness of cognitivebehavioural family intervention in reducing the burden of care in carers of patients with Alzheimer's disease. Br J Psychiatry 2000;176:557-62.

23 Watts S, Kaiser P, Porter J, et al. A psychological group approach to meeting the needs of people with Parkinson's disease and carers. In: Percival R, Hobson P, eds. Parkinson's Disease: Studies in Psychological and Social Care. Leicester: BPS Books, 1999:199-216.

24 Goldberg D. General Health Questionnaire. Windsor: NFER-Nelson, 1978.

25 Sheikh JA, Yesavage JA. Geriatric Depression Scale (GDS): recent findings and development of a shorter version. In: Brink TL, ed. Clinical Gerontology: a guide to assessment and intervention. New York: Howarth Press, 1986.

26 Robinson BC. Validation of a caregiver strain index. J Gerontol 1983;38:344-8.

27 Novak M, Guest C. Application of a multidimensional caregiver burden inventory. Gerontologist 1989;29:798-803.

28 Multidimensional functional assessment: the OARS methodology. Durham, NC: Duke University, 1975.

29 Hoehn MM, Yahr MD. Parkinsonism: onset progression and mortality. Neurology 1967;17:427-42.

30 Schwab RS, England AC. Projection technique for evaluating surgery for Parkinson's disease. In: Gillingham FJ, Donaldson MC, eds. Third Symposium on Parkinson's Disease. Edinburgh: E\&S Livingstone, 1969. 
31 Molloy DW, Alemayehu E, Roberts R. Reliability of a Standardized MiniMental State Examination compared with the traditional Mini-Mental State Examination. Am J Psychiatry 1991;148:102-5.

32 Hughes CP, Berg L, Danziger WL. A new clinical scale for the staging of dementia. Br J Psychol 1982;140:566-72.

33 Teri L, Logsdon RG, Uomoto J, et al. Behavioral treatment of depression in dementia patients: A controlled clinical trial. J Gerontol 1997;52:P159-P166.

34 Laidlaw K, Thompson LW, Dick-Siskin L, et al. Cognitive behaviour therapy with older people. NY: John Wiley \& Son, 2003

35 Charlesworth EA, Nathan RG. Relaxation procedures for stress management In: Russell ML, ed. Stress Management for Chronic Disease. USA: Pergamon, 1988:65-79.

36 Beck AT, Rush AJ, Shaw BF, et al. Cognitive therapy of depression. New York: Guildford Press, 1979.

37 Greenberger D, Padesky CA. Mind over mood: change how you feel by changing the way you think. New York: The Guildford Press, 1995.

38 Bootzin RR. Cognitive-behavioral treatment of insomnia: Knitting up the ravell'd sleeve of care. In: Kenny DT, Carlson J, eds. Stress and health: Research and clinical applications. USA: Routledge, 2000:243-66.

39 Matthews JN, Altman DG, Campbell MJ, et al. Analysis of serial measurements in medical research. BMJ 1990;300:230-5.

40 Aarsland D, Larsen JP, Karlsen KH, et al. Mental symptoms in Parkinson's disease are important contributors to caregiver distress. Int J Geriatr Psychiatry 1999;14:866-74.

41 Berry RA, Murphy JF. Well-being of caregivers of spouses with Parkinson's disease. Clin Nurs Res 1995;4:373-86.

42 Ellgring $H$, Seiler S, Perleth B, et al. Psychosocial aspects of Parkinson's disease. Neurology 1993;43:S41-S44.
43 Happe S, Berger K. The association between caregiver burden and sleep disturbances in partners of patients with Parkinson's disease. Age Ageing 2002;31:349-54

44 Seiler S, Perleth B, Gasser T, et al. Partnership and depression in Parkinson's disease. Behav Neurol 1992:5:75-81.

45 Thommessen B, Aarsland D, Braekhus A, et al. The psychosocial burden on spouses of the elderly with stroke, dementia and Parkinson's disease. Int J Geriatr Psychiatry 2002; 17:78-84.

46 MacCarthy B, Brown R. Psychosocial factors in Parkinson's disease. Br J Clin Psychol 1989;28:41-52.

47 Almeida OP, Almeida SA. Short versions of the geriatric depression scale: a study of their validity for the diagnosis of a major depressive episode according to ICD-10 and DSM-IV. Int J Geriatr Psychiatry 1999;14:858-65.

48 Aneshensel CS, Pearlin LI, Mullan JT, et al. Profiles of caregiving: The unexpected career. New York: Academic Press, 1995.

49 Powers DV, Gallagher-Thompson D, Kraemer HC. Coping and depression in Alzheimer's caregivers: longitudinal evidence of stability. J Gerontol B Psychol Sci Soc Sci 2002;57:205-11.

50 Gallagher-Thompson D, Steffen AM. Comparative effects of cognitivebehavioral and brief psychodynamic psychotherapies for depressed family caregivers. J Consult Clin Psychol 1994;62:543-9.

51 Collins C, Jones R. Emotional distress and morbidity in dementia carers: A matched comparison of husbands and wives. Int J Geriatr Psychiatry 1997; 12:1168-73.

52 Miller B, Cafasso L. Gender differences in caregiving: fact or artifact? Gerontologist 1992;32:498-507.

53 DeVries HM, Hamilton DW, Lovett S, et al. Patterns of coping preferences for male and female caregivers of frail older adults. Psychol Aging $1997 ; 12: 263-7$. 